\title{
Yenidoğanda Dirençli Supraventriküler Taşikardi Olgusu
}

\author{
Gülten Acehan® $\odot$, Baran Cengiz Arcagök $\odot$
}

Acıbadem Fulya Hastanesi, Yenidoğan Yoğun Bakım Ünitesi, İstanbul, Türkiye

Gülten Acehan, Uzm. Hemş. Baran Cengiz Arcagök, Uzm. Dr.

Illetişim:

Uzm. Hemş. Gülten Acehan Acıbadem Fulya Hastanesi, Yenidoğan Yoğun Bakım Ünitesi, İstanbul, Türkiye

Tel: +902123064636

E-Posta: g-acehan@hotmail.com

Gönderilme Tarihi : 060 cak 2017

Revizyon Tarihi : 12 Haziran 2017

Kabul Tarihi : $\quad 15$ Haziran 2017

\section{ÖZET}

Supraventriküler taşikardi yenidoğan döneminde diğer yaş grubu çocuklara göre klinik olarak daha ağır seyretmektedir. Hastaları sinüs ritmine döndürmek için ilaç tedavisi, senkronize kardiyoversiyon, ablasyon tedavisi gibi yöntemler kullanılmaktadır. Bu makalede yenidoğanda çeşitli antiartitmik ajanlara ve senkronize kardiyoversiyona yanıt alınamayan dirençli supraventriküler taşikardi olgusu sunulmuş ve antiaritmik ilaçların dikkatli kullanılması, senkronize kardiyoversiyona bağlı ciddi komplikasyonların önlenmesi için hazırlık sürecinin ve atakların tekrarlanmasını önlemek için taburculuk eğitim sürecinin önemi vurgulanmıştır.

Anahtar sözcükler: Supraventriküler taşikardi, yenidoğan, tedavi

\section{THE PHENOMENON OF PERSISTENT SUPRAVENTRICULAR TACHYCARDIA IN THE NEWBORN}

\section{ABSTRACT}

Supraventricular tachycardia is more severe in newborns when compared to children from other age groups. Methods such as medical treatment, synchronized cardioversion, and ablation treatment are used in order to restore the patients to sinus rhythm. In this article, the phenomenon of persistent supraventricular tachycardia in newborns, in which a response cannot be obtained form various antiarrhythmic agents and synchronized cardioversion, is presented. Furthermore, the significance of the preparation process in order to provide careful administration of antiarrhythmic drugs, the prevention of severe complications based on synchronized cardioversion and the significance of discharge training process in order to prevent the recurrence of the attacks are emphasized.

Keywords: Supraventricular tachycardia, Newborn, Treatment

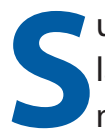
upraventriküler taşikardi (SVT) yenidoğan döneminde diğer yaş grubu çocuklara göre daha ender olarak görülmekle birlikte klinik olarak daha ağır seyretmektedir $(1,2)$. Yenidoğanda kardiyak monitorizasyonun artmasıyla birlikte ritim anormalliklerine daha sık tanı konulmaktadır. En sık gözlenen ritim bozuklukları bradikardi ve prematüre atımlar olup elektrokardiyografide (EKG) \%1-5 oranında saptanmaktadır. Primer kardiyak patolojiler dışında sepsis, santral sinir sistemi hastalıkları, adrenal yetmezlik, elektrolit dengesizlikleri, hipoglisemi, metabolik asidoz ya da metabolik alkaloz gibi tıbbi sorunlar da ikincil olarak aritmiye neden olabilmektedir. Eşlik eden tıbbi sorunlar ile birlikte aritmiler, yenidoğanda yüksek morbidite ve mortalite nedenidir. Yenidoğan dönemindeki ritim bozuklukları kalp yetersizliği, kardiyojenik şok ve ölüm gibi ağır tablolar ile sonuçlanabilmektedir (3). 
Tedavide acil yaklaşım hayat kurtarıcı olup büyük önem taşımaktadır. Vagal uyarı (yüze buz uygulaması), ilaç tedavisi (adenozin, esmolol, digoksin, sotalol, propanolol, amiodaron), ilaç tedavilerine yanıtsız ve hemodinamik durumu kötü olan hastalarda direkt akım senkronize kardiyoversiyon, transözefageal veya atrial hızlı pil uyarısı uygulaması ve katater ablasyonu diğer tedavi seçenekleridir $(1,3,4)$. Senkronize direkt akımlı kardiyoversiyon ilk kez 1962'de Cown ve arkadaşlarının bildirdiği bir SVT olgusunun tedavisinden bu yana kullanılan bir yöntemdir. Yenidoğan döneminde ise ilk kez 1965 yılında Hassenruck ve ark. tarafından bir Atriyal Flatter olgusunda başarı ile kullanılmıştır (5)

Kardiyoversiyona bağlı olası ciddi komplikasyonlar (ventriküler fibrilasyon, fonksiyonel veya morfolojik miyokard hasarı, sistemik veya pulmoner emboli gibi) nedeniyle (6) ritmin düzeltilmesi aşamasında monitörizasyon, acil IV yolun açılması, solunumun değerlendirilmesi ve ihtiyaca göre solunum desteği sağlanması ve genel durum takibi önemli hayat kurtarıcı hemşirelik uygulamalarıdır. Gerilemeyen inatçı ataklarda kardiyoversiyonun uygulanması için defibrilatörün hazırlanması müdahalenin etkinliği ve hızı için önemlidir. Vakalar yoğun bakım şartlarında pediatrik kardiyologlar ile birlikte multidisipliner bir yapıda izlenmelidir (3).

Bu makalede postnatal 16. Saatinde Solunum Distresi gelişmesi nedeni ile yoğun bakım ünitesinde takibi başlatılan ve postnatal 6.gününde beslenme sonrasında SVT gelişen bir olgu literatür bilgileri ile tartışılmıştır.

\section{Olgu sunumu}

Antenatal izleminde sorunu olmayan 31 yaşındaki primipar anneden 40. gebelik haftası+3 günde indüksiyonlu normal vajinal yol ile 3585 gr ağırlığında doğurtulan bebek postnatal 16. saatinde taşipnesi, interkostal ve subkostal çekilmelerinin saptanması üzerine Yenidoğanın Solunum Sıkıntısı nedeni ile Yenidoğan Yoğun Bakım Ünitesine (YYBÜ) yatışı yapılarak monitörize izlemine başlanmıştır. Yatışında kalp tepe atımı 132/dk., saturasyonu $\% 95$, ateş $36,5^{\circ} \mathrm{C}$, dakika solunum sayısı $72 / \mathrm{dk}$. idi. Akciğerlerinde dinlemekle bilateral subkrepitan raller mevcut. Anal bölge ile sakrum arasında skin tag mevcut idi. Diğer sistem muayenelerinde ek özellik görülmedi. Akciğer grafisi normaldi. Venöz kan gazında $\mathrm{pH} 7.35, \mathrm{PCO}_{2}$ $44 \mathrm{mmHg}, \mathrm{HCO}_{3} 23.2 \mathrm{meq} / \mathrm{L}, \mathrm{BE}-0,8$ idi. Tam kan sayımında hemoglobin $19.9 \mathrm{gr} / \mathrm{dL}$, hemotokrit \%56.4, lökosit $12.98 \times 10^{3} / \mu \mathrm{L}$, trombosit $17010 \wedge 3 / \mathrm{ul}, \mathrm{C}$ reaktif protein (CRP) $2.11 \mathrm{mg} / \mathrm{dL}$, kan biyokimyasl; böbrek ve karaciğer fonsiyon tetleri ile elektrolitleri normal idi. Damar yolu açıldı, kültür örnekleri alındı ve Sepsis olarak değerlendirilerek antibiyotik tedavisi başlandı. Solunum sıkıntısı olduğu için oral beslenmesi kesilerek $70 \mathrm{ml} / \mathrm{kg} / \mathrm{gün}$ 'den glukoz perfüzyon hızı $6 \mathrm{mg} / \mathrm{kg} / \mathrm{dk}$ olacak şekilde dekstroz infüzyonu başlandı. Takibinin 2. gününde solunum sıkıntısı geriledi. Enteral beslenmeye anne sütü ve formula desteği ile $30 \mathrm{ml} / \mathrm{kg} /$ gün'den başlandı ve kademeli artırılarak 4. günde tam enteral beslenmeye geçildi. Emzirmesi desteklendi. Tartı alımı mevcut, idrar ve gaita çıkışı normal olduğu görüldü. Takibinin 6 . gününde beslenme sonrası monitörizasyonunda 200-220 /dk arasında seyreden taşikardisinin olması üzerine EKG'de $p$ dalgaları yoktu, dar QRS mevcut idi. SVT ile uyumlu olarak değerlendirildi. EKG'de SVT saptanması üzerine bebeğe kalbe en yakın bölge olması düşünülerek sol kol antekübital bölgeden acil intravenöz (IV) yol açıldı (Şekil 1). $50 \mathrm{mcg} / \mathrm{kg}$ adenozin hızlı IV bolus yapıldı. Cevap alınamayınca sırasıyla $100 \mathrm{mcg} / \mathrm{kg}, 200 \mathrm{mcg} / \mathrm{kg}$ ve $300 \mathrm{mcg} / \mathrm{kg}$ adenozin yapıldı. Her adenozin uygulaması sonrasında $5 \mathrm{ml}$ serum fizyolojik (SF) IV bolus olarak uygulandı. Tedaviye yanıt alınmadığı ve SVT bulgularının devam ettiği gözlendi. Hastanın dolaşımının bozulmaması ve hemodinamisinin stabil olması nedeni ile senkronize kardiyoversiyon yapılmadı. Esmolol $0,5 \mathrm{mg} / \mathrm{kg} 1$ dakikalık IV bolus olarak uygulandı ve sonrasında $0,05 \mathrm{mg} / \mathrm{kg} / \mathrm{dk} 4$ dakikalık infüzyon uygulandı. Esmolol tedavisine rağmen hastanın kalp tepe atımı 200$220 / \mathrm{dk}$ arasında seyrettiği için $5 \mathrm{mg} / \mathrm{kg}$ amiodaron $30 \mathrm{da}$ kikalık yükleme dozundan sonra $5 \mathrm{mg} / \mathrm{kg} / \mathrm{gün}$ amiodaron infüzyonu başlandı. Amiodaron yükleme tedavisi sonrasında bebeğin kalp tepe atımı 150 dk'ya geriledi. Pediatrik Kardiyologa danışılarak amiodaron infüzyonuna devam edildi. Ekokardiyografisi (EKO) planlandı. Amiodaron infüzyonunun 10. saatinde tekrar SVT atağının gelişmesi üzerine 10 mg/kg/gün'e artırıldı. Pediatrik Kardiyolog tarafından muayenesi sonrasında $10 \mathrm{mg} / \mathrm{kg} / \mathrm{gün}$ Amiodaron infüzyonuna rağmen SVT'nin devam etmesi üzerine senkronize kardiyoversiyon uygulanmasına karar verildi. Aileden bilgilendirme sonrası onam alındıktan sonra kardiyoversiyon hazırlığı yapıldı. Kardiyoversiyonun sedasyon ve analjezi gerektiren ağrılı bir işlem olması nedeni ile işlem öncesi bebeğe $0,1 \mathrm{mg} / \mathrm{kg}$ midazolam IV bolus uygulandı. Anterolateral yerleşimde $0,5 \mathrm{j} / \mathrm{kg}$ senkronize kardiyoversiyon uygulandı. İlk kardiyoversiyona rağmen aritmik olan kalp atımlarının görülmesi üzerine sırasıyla $1 \mathrm{j} /$ kg ve $2 \mathrm{j} / \mathrm{kg}$ senkronize kardiyoversiyon uygulandı. Tekrar yanıt alınamaması üzerine $2 \mathrm{j} / \mathrm{kg}$ anterior posterior yerleşimli senkronize kardiyoversiyon uygulandı ancak tekrar yanıt alınamadı. Hastaya Sotalol $2 \mathrm{mg} / \mathrm{kg} / \mathrm{gün} 2$ dozda alacak şekilde peroral (PO) olarak başlandı. illk dozun uygulanmasından yaklaşık 10 dakika sonra kalp hızı düşmeye 
başladı ve 30 dakika içinde normal sinüs ritmine döndüğü görüldü (Şekil 2). Amiodaronun neden olabileceği hipotiroidi açısından takibinin 8 . gününde tiroid fonksiyon testleri değerlendirildi ve normal olduğu saptandı. Kan kültüründe üreme olmadı, antibiyotik tedavisi sonlandırıldı. Tam enteral olarak beslenen, fizik muayenesi normal olan, tekrarlayan SVT atağı olmayan ve EKG'sinde normal sinüs ritmi saptanan bebek Pediatrik Kardiyoloji ile görüşülerek Sotalol tedavisine devam edilerek kontrole gelmek üzere taburculuk eğitimi verilerek taburcu edildi. Taburculuk sonrası ileri dönemde tedavinin düzenli uygulanması da atakların tekrarlamasını engellemektedir. Bu nedenle kontroller sırasında ilaç kullanımı dikkatli bir şekilde sorgulanmalı ve ailelere önemi tekrar hatırlatılmalıdır (3). Hastamı sotalol tedavisiyle kontrole gelmek üzere taburculuk eğitimi verilerek taburcu edildi. İlaç kullanım eğitimi aileden geri bildirim alınarak ayrıntılı olarak anlatıldı.

\section{Tartışma}

SVT yenidoğan dâhil çocukluk çağının en sık görülen aritmi türüdür. Prenatal dönemde taşikardi, postnatal dönemde huzursuzluk, emme bozukluğu, taşipne, taşikardi ve kalp yetersizliği ile ortaya çıkabilir. Birçok yenidoğan SVT'yi ilk saatlerde tolere etmekle birlikte 6-12 saatten daha fazla süren olgularda kalp atım hacminin azalması sonucunda kalp yetersizliği gelişebilmektedir (4). Hastaların \%15'inde sepsis ve ilaç kullanımı öyküsü vardır $(1,4,7)$. Bizim hastamızda da sepsis tanısı mevcut idi. Yapılan EKO incelemesinde aritmiye zemin hazırlayabilecek yapısal kalp hastalığı saptanmadı.

Aydın ve ark. çocuklarda yüze buzlu su uygulaması ile vagal uyarıya yanıtı \%96 gibi yüksek bir orandayken, diğer çalışmlarda \%33-62 arasında değişen bir başarı oranı bildirilmektedir. Üçsel ve ark. tarafından yapılan çalışmada ise vagal uyarının \%10 oranında sonuç verdiği bildirilmiştir (8). Hastamıza vagal manevra uygulaması yapılmadı.

Akut atak tedavisinde seçilecek yöntem ve ilaçlarla ilgili ortak bir yaklaşım henüz yoktur (1). Adenozin, yarılanma ömrü kısa olmasına rağmen SVT tedavisinde en etkili farmakolojik ajandır (9). Çocuklarda adenozine 50 $\mu \mathrm{g} / \mathrm{kg}$ dozunda IV hızlı puşe şeklinde başlanmasını ve yanıt vermediğinde $50 \mathrm{mcg} / \mathrm{kg}$ dozunda artırılarak süt

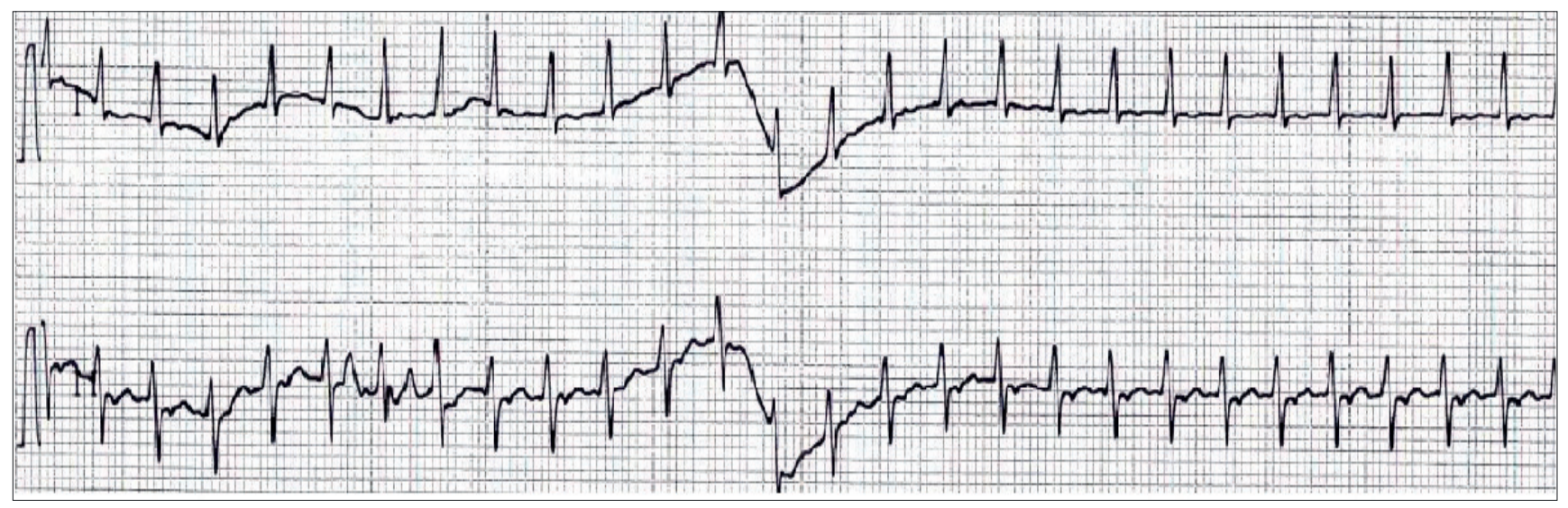

Şekil 1. EKG'de P Dalgası Olmayan Supraventriküler Taşikardi

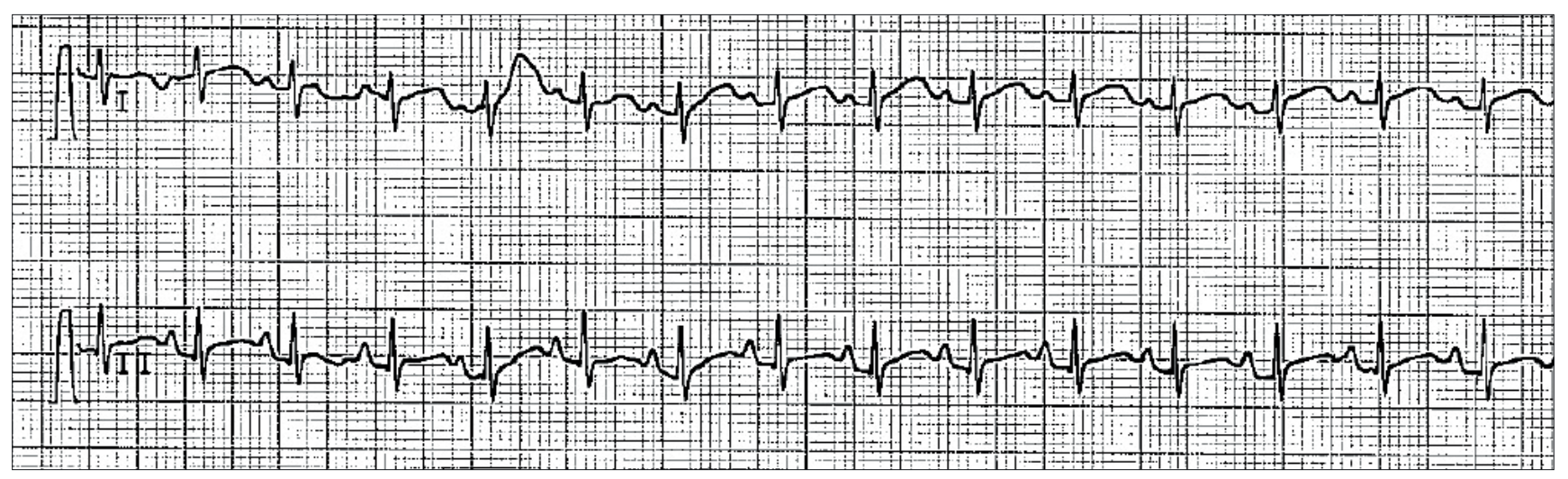

Şekil 2. EKG'de Normal Sinüs Ritmi 
çocuklarında en yüksek $300 \mathrm{mcg} / \mathrm{kg}$ dozunda kullanılması önerilmektedir (1). Bizim olguda da $50 \mathrm{mcg} / \mathrm{kg}$ adenozin hızlı IV bolus yapıldı. Yanıt alınamayınca sırasıyla $100 \mathrm{mcg} /$ $\mathrm{kg}, 200 \mathrm{mcg} / \mathrm{kg}$ ve $300 \mathrm{mcg} / \mathrm{kg}$ adenozin yapıldı fakat SVT atağı durdurulamadı.

Akdeniz ve ark. tarafından Adenozine dirençli SVT atağı sonrası esmolol başarılı bir şekilde kullanılmıştır. Fakat hastamızda esmolol tedavisine de yanıt alınamadı. Amiodaronun tek başına veya propranolol ve flekainid ile kombinasyonu dirençli SVT'lerin tedavisinde başarılı bulunmuştur. Bebeklerde dirençli SVT tedavisinde amiodaron ile birlikte digoksin kullanımını öneren araştırmacılar da vardır (10). Uzun ve yüksek dozda amiodaron kullanımında özellikle erişkinlerde tiroid disfonksiyonu, pulmoner fibrozis, hepatotoksisite, dispeptik semptomlar, korneal depolanma sonucu görmede bozukluklar ve deride döküntüler geliştiği bildirilmektedir. Hastamızda Esmolol tedavisine yanıt alınamadığı için amiodaron 30 dakikalık yükleme dozundan sonra $5 \mathrm{mg} / \mathrm{kg} /$ gün infüzyon başlandı. Amiodaron yükleme tedavisi sonrasında bebeğin kalp tepe atımı 150 dk'ya geriledi. Amiodaron infüzyonunun 10. saatinde tekrar SVT atağının gelişmesi üzerine 10 mg/kg/gün'e artırıldı. 10 mg/ $\mathrm{kg} / \mathrm{gün}$ amiodaron infüzyonuna rağmen SVT kontrol altına alınamadı. Olgumuzda amiodaron tedavisi esnasında ve tedavi sonrası her hangi bir yan etki görülmedi.

Literatür incelendiğinde yenidoğanlarda çoğu olgunun dijitalizasyon veya elektriksel kardiyoversiyon ile kolaylıkla sinüs ritmine döndürülebilir olduğu görülmektedir

\section{Kaynaklar}

1. Bolat F, Uslu S, Cömert S, Dindar A, Bülbüln A, Nuhoğlu A. A Case Report with Neonatal Supraventricular Tachycardia: Review of Current Treatment. Çocuk Dergisi 2010; 10:51-4. [CrossRef]

2. Turan Ö, Akyol B, Gemici B, Akşahin B, Sazak S, Ziya Yurdakul. Management of Supraventricular Tachycardia: Two Cases, Two Different Clinical Outcomes. The Journal of Pediatric Research 2014;1:158-60. [CrossRef]

3. Metreş Ö. Supraventricular Tachycardia in Newborns and Nursing Approach: A Case Report. Türk Kardiyol Dern Kardiyovasküler Hemşirelik Dergisi 2014;5:89-92. [CrossRef]

4. Konak M, Annagür A, Şap $F$, Altunhan $H$, Tarkçı $N$, Örs R. Supraventricular Tachycardia Developed in a Newborn Receiving Caffeine Therapy Due To Premature Apnea. Selçuk Tıp Dergisi 2014;30:34-5.

5. Özdemir R, Altuğ N, Dizdar EA, Yurttutan S, Öncel MY, Erdeve Ö, et al. A Case of Atrial Flutter Treated by Cardioversion in a Premature Newborn. Türkiye Çocuk Hastalıkları Dergisi 2013;1:47-9. [CrossRef]

6. Hakan N, Aydın M, Örün UA, Kanık S, İpek MŞ, Okumuş N, et al. White Syndrome Presented with Different Clinical Manifestations. Cocuk Dergisi 2011;11:81-5. [CrossRef]
$(2,5,11)$ Hastamızın SVT atağı çeşitli antiaritmik ajanlar kullanılmasına rağmen kontrol altına alınamadığı için senkronize kardiyoversiyon uygulandı literatürden farklı olarak yanıt alınamadı.

Kardiyoversiyon öncesi premedikasyon önerilmektedir $(12,13)$. Hastamıza $0,1 \mathrm{mg} / \mathrm{kg}$ midazolam IV bolus uygulandı. Her anestezik ajanın az veya çok solunum deprese edici etkisinin olduğu, özellikle hızlı IV enjeksiyonların ani hemodinamik değişikliklere yol açabileceği unutulmaksızın kullanılan ajanların yeterli monitörizasyon sağlandıktan sonra titre edilerek verilmesi ve mutlaka işlemin acil havayolu sağlayabilecek, hemodinamik değişikliklere hızla müdahale edilebilecek ortamlarda gerçekleştirilmelidir (13). Olgumuzda işlem öncesinde, sırasında ve sonrasında tüm hazırlık eksiksiz yapılmıştır ve kayıt altına alınmıştır.

Kardiyoversiyona yanıt alınamayınca B-adrenerjik bloker olan Sotalol tedavisi başlandı. Hastamızda ilk dozun uygulanmasından yaklaşık 10 dakika sonra kalp hızı düşmeye başladı ve 30 dakika içinde normal sinüs ritmine döndüğü görüldü.

Yenidoğanda SVT tedavisi zor olmakla birlikte akut atak tedavisinde seçilecek yöntem ve ilaçlarla ilgili ortak bir yaklaşım henüz yoktur. Tedavide kullanılan farklı ilaçlar servislerde hazır bulundurulmalı, kardiyoversiyon öncesi acil müdahale hazırlığı yapılmalı ve olgular yoğun bakım şartlarında multidisipliner bir yapıda takip edilmelidir.

7. Kantoch MJ. Supraventricular tachycardia in children. Indian J Pediatr 2005;72:609-19.

8. Üçsel R, Çıtak A, Karaböcüoğlu M, Aydın F, Ömeroğlu R, Uzel N. Acute management of supraventricular tachycardia in pediatric patients. İst. Tıp Fak. Mecmuası 2000;63:382-6.

9. Can E, Bülbül A, Bülbül LG, Nuhoğlu A. Supraventricular tachycardia responding to amiodarone developed during umblical vein catheterization. Ege Tıp Dergisi 2010; 49:205-7.

10. Akdeniz C, Kıplapınar M, Sengül FS, Tuzcu V. Successful catheter ablation in a newborn with supraventricular tachycardia resistant to medical therapy. Anadolu Kardiyoloji Dergisi 2012; 12:1-3.

11. Paç A, Çeliker A, Bilgiç A. A Case of Atrial Flutter Treated by Cardioversion in a Newborn. T Klin Kardiyoloji 1993;6:169-71.

12. Badır A. Are we Performing Defibrillation and Cardioversion Correctly? Hemşirelikte Eğitim ve Araştırma Dergisi 2005; 2:17-23.

13. Köse EA, Apan A. Electrical External Cardioversion and Sedation. Türk Aritmi, Pacemaker ve Elektrofizyoloji Dergisi 2011;9:7-12. 